\title{
PHYSICS IN DAILY LIFE: COUNTING FLAMES
}

\section{L.J.F. (Jo) Hermans,}

Leiden University•The Netherlands.Email: Hermans@Physics.LeidenUniv.nl

A sk any layman this simple question: "If you run your hotwater tap, you are using energy, right? How many lights do you think you could switch on from that energy during the same time?"

The answer will probably be something like: "Well, let's see, I guess 10 , or perhaps even 20 ". He or she will be surprised if we say that it may be as many as 1000 .

The layman does not know that the specific heat capacity of water is remarkably high. And he or she does not realize the full extent of the first law of thermodynamics.

For us physicists, it's easy. We could even explain things by counting flames, knowing that a small flame produces about 100 watts. Take a match. Its mass is about 0,1 gram and therefore its wood contains roughly $2 \mathrm{~kJ}$.

Now just assume that it burns for about 20 seconds, and there you go: $2000 \mathrm{~J} / 20 \mathrm{~s}=100 \mathrm{~W}$. For a candle we can do the same exercise. Find out for how long it will burn, look up the heat of combustion of paraffin or stearine, and again: about $100 \mathrm{~W}$. So the rule of thumb is simple: a small flame is a heater of about 100 watts.

From here it's downhill. First let us look at a camping gas cooker, or - if we use natural gas at home - at the

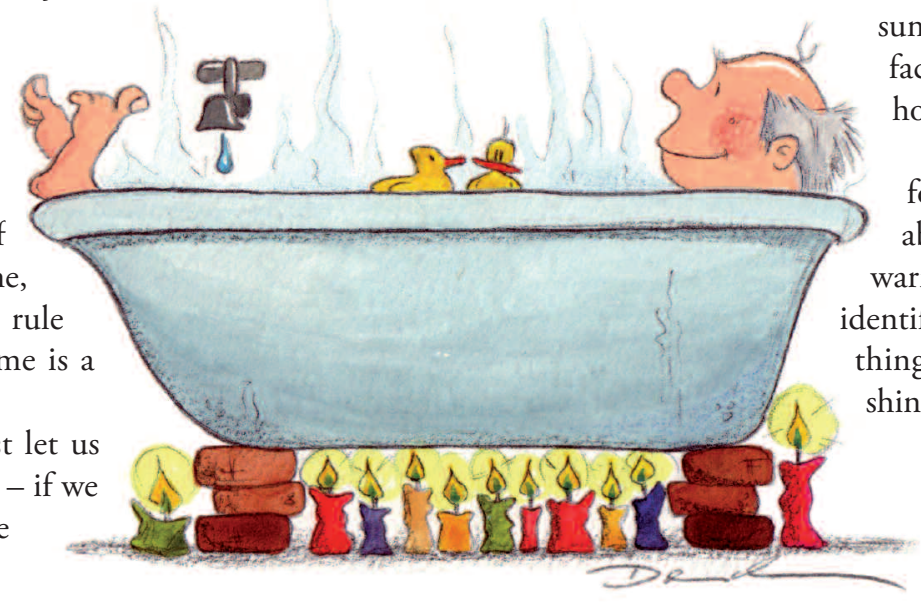

28. volume 39. number 2 gas stove. Each burner has 20 to 30 flames, so a burner should produce 2 to $3 \mathrm{~kW}$ of heat. And sure enough: if we look it up on the internet, Google tells us that our guess was right. For a hot water tap, though, that is not enough. If we happen to be familiar with gas geysers, we remember that they have about 10 rows of 10 flames. That makes $100 \times 100 \mathrm{~W}$ or $10 \mathrm{~kW}$. And the gas geyser isn't even a device of great luxury. It has too small a capacity to produce a decent shower, for example. It is therefore safe to assume that an average hot water tap will easily exceed those $10 \mathrm{~kW}$.

But let us not overdo things, and stick to $10 \mathrm{~kW}$. And let us for simplicity assume that the water is heated electrically, so we can directly compare that to electric lighting. An efficient light source producing 600 lumen consumes $11 \mathrm{~W}$. That is, indeed, a factor of 1000 lower than the hot-water tap.

This is a nice little lesson for any layman concerned about energy and global warming. Most often, he or she identifies energy use at home with things that turn or things that shine: electric motors or lighting.

Wrong. It's not motion. It's not light. Heat is our guide.

Article available at http://www.europhysicsnews.org or http://dx.doi.org/10.1051/epn:20082007 